\title{
A High-Temperature Cell Assembly for Absorption Spectroscopy and Absorption Spectra of Palladium(II) in Fused Lithium Chloride-Potassium Chloride Eutectic*
}

\author{
By Shin Suzuki** and Kôichi Tanaka**
}

\begin{abstract}
A high-temperature cell assembly attached to a Hitachi Model EPU-2A spectrophotometer was constructed to measure the absorption spectra of fused salt solutions. The measurable spectrum range of this instrument is 50000 to $5000 \mathrm{~cm}^{-1}$ over the temperature range from $300^{\circ}$ to $890^{\circ} \mathrm{C}$.

Absorption spectra of $\mathrm{Pd}(\mathrm{II})$ in fused LiCl-KCl eutectic were measured in the spectrum range from 29000 to $10000 \mathrm{~cm}^{-1}$ at various temperatures between $400^{\circ}$ and $700^{\circ} \mathrm{C}$. Only one absorption band was found at $20200 \mathrm{~cm}^{-1}$ and its molar absorptivity was 315 at $400^{\circ} \mathrm{C}$. An increase in temperature caused both a shift of the absorption maximum to a lower wave number and an increase in molar absorptivity. Some discussions on the species of $\mathrm{Pd}(\mathrm{I})$ in this solvent are made in comparison of these results and absorption spectra of $\mathbf{P d}(\mathrm{II})$ in aqueous solutions of high chloride concentration.

(Received March 2, 1970)
\end{abstract}

\section{Introduction}

The spectrophotometric investigation is one of the excellent methods for the understanding of ionic species and its behavior in fused salt solutions. Since the first success of the accurate measurement of the absorption spectra of fused salt solutions by Gruen et al. in $1956^{(1)}$, a number of the absorption spectra of $3 \mathrm{~d}, 4 \mathrm{f}$ and $5 \mathrm{f}$ series transition metal ions in fused nitrates, sulfates, chlorides, and fluorides have been measured by several groups of workers ${ }^{(2)}$.

However, as to the absorption spectra of $4 \mathrm{~d}$ and $5 \mathrm{~d}$ series transition metal ions, there are no detailed studies except the measurements of the absorption spectra of $\mathrm{Rh}(\mathrm{III}), \mathrm{Ir}(\mathrm{III})^{(3)}, \mathrm{Pd}(\mathrm{II}), \mathrm{Pt}(\mathrm{II})^{(3)(4)}, \mathrm{Re}(\mathrm{III})$ and $\mathrm{Re}$ $(\mathrm{IV})^{(5)}$ in fused $\mathrm{LiCl}-\mathrm{KCl}$ eutectic. In general, much of the knowledge concerning the behavior of the ionic species of $4 \mathrm{~d}$ and $5 \mathrm{~d}$ series metallic elements remain unexplained even in aqueous solutions because of the complication caused by many valency states exhibited by these elements. The behavior of ionic species in fused salt solutions is assumed to be simpler than that in aqueous solutions because in the former there are no complicate reactions with polar molecules. If we viewed from another angle, a fused salt solution is considered to be the extreme case of a concentrated aqueous solution in the ligand ion concentration. Consequently, it is expected that the significant information regarding the formation of these metal complexes and their structures may be obtained by comparing the absorption spectra in fused salt solutions with those in aqueous soluions.

The authors have been investigating the species and the structure of the platinum group elements present in

* Published previously in Japanese in Journal of the Japan Institute of Metals, 32 (1968), 470. Presented at the 20 th Annual Meeting of the Chemical Society of Japan, April, 1967.

** The Research Institute for Iron, Steel and Other Metals, Tohoku University, Sendai, Japan.

(1) D. M. Gruen : Nature, 178 (1956), 1181

(2) (a) D. M. Gruen and R. L. McBeth : Pure Appl. Chem., 6 (1963), 23; (b) G. P. Smith : Molten Salt Chemistry, John Wiley, New York, (1964), p. 427. fused salt solutions. In this paper, a high-temperature cell assembly was constructed and the absorption spectra of $\mathrm{Pd}(\mathrm{II})$ in fused $\mathrm{LiCl}-\mathrm{KCl}$ eutectic were measured by a spectrophotometer equipped with this apparatus. The species of $\mathrm{Pd}(\mathrm{II})$ in the eutectic was inferred by the comparison of the absorption spectra in this medium with those in aqueous solutions.

\section{Apparatus and Reagents}

Absorption spectra were measured with a Hitachi Model EPU-2 A spectrophotometer equipped with a hightemperature cell assembly. In order to minimize the effect of the black-body radiation from a furnace, a sample, and a sample container at high temperature, the positions of the monochrometer and the cell housing of the spectrophotometer were reversed; that is, the light source, the cell housing, the monochrometer, and the detector were arranged in this order. With this modification, the resolving power of the spectrophotometer was slightly lost, but it had been demonstrated that the quantitative spectrophotometric measurements could be made up to $850^{\circ} \mathrm{C}$ without the unfavorable effect due to the black-body radiation ${ }^{(6)}$.

A high-temperature cell assembly consists of a furnace core and an outer box as shown in Fig. 1 (a) and (b). The furnace core is composed of a furnace block, a heater, a Chromel-Alumel thermocouples, and insulation bricks. The furnace block is made of stainless steel which is a good conductor of heat and also a good resistant against. the corrosion by gases generated by the decomposition of fused salts. The heater consisted of four silundum rods which are connected in parallel is put into the furnace block. The maximum applied voltage is $65 \mathrm{~V}$ and the established temperature of the furnace is attained within

(3) J. R. Dickinson and K. E. Johnson : Can. J. Chem., 45 (1967), 1631.

(4) R. A. Bailey and J. A. McIntyre : Inorg. Chem., 5(1966), 1824.

(5) R.A. Bailey and J. A. McIntyre : ibid, 5 (1966), 964, 1940.

(6) D. M. Gruen and R. L. McBeth : J. Inorg. Nucl. Chem., 9 (1959), 290. 


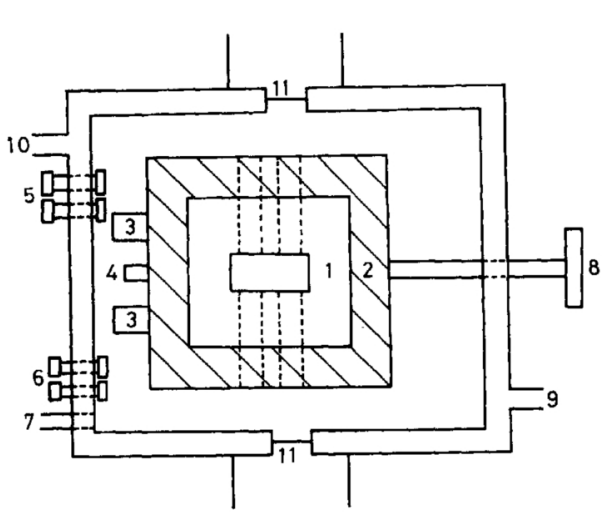

(a) Upper view

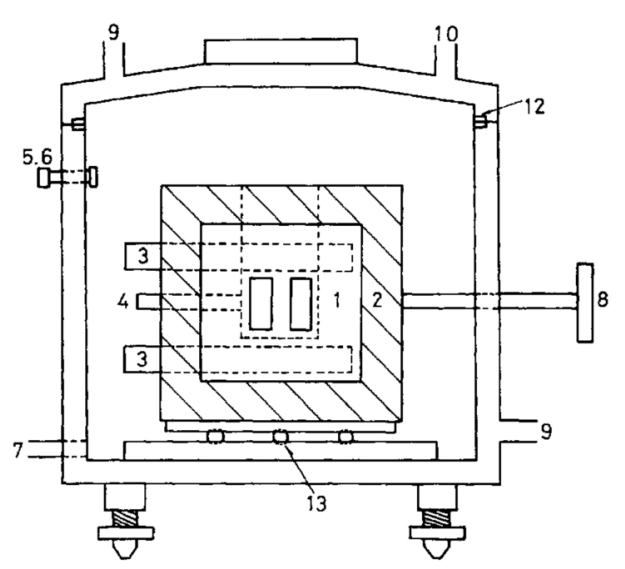

(b) Side view

Fig. 1 High temperature cell assembly.

1 : Stainless steel block 2 : Heat insulation brick

3: Heater 4: Thermocouple 5: Heater terminal

6 : Thermocouple terminal 7 : Inert gas inlet $8:$ Cell

holder knob $9:$ Water inlet $10:$ Water outlet

11 : Quartz window 12 : Packing $13:$ Ball bearing

an hour. The control of the furnace temperature is made by a Hitachi automatic temperature control unit. By this device, it has become feasible to measure the absorption spectra at any temperature between $300^{\circ}$ and $890^{\circ} \mathrm{C}$ and the furnace is maintained at the required temperature within the accuracy of $1 \%$. The outer box is cooled by circulating water and a pair of optically grinding quartz glass plates is placed at each exit of the light path from the box in order to protect the light source and the monochrometer from heating by the furnace. A condensing lens is placed outside of the quartz glass to focus the light beam on the entrance slit of the monochrometer. A I-cm quartz cell, which was placed in the cell holder made of stainless steel, was used in measuring the absorption spectra.

Reagent grade $\mathrm{LiCl}$ and $\mathrm{KCl}$ from Wakô Pure Chemical Industries, Ltd. were used without further purifications. $\mathrm{K}_{2} \mathrm{PdCl}_{4}$ was prepared from $\mathrm{Pd}$ metal $(99.9 \%$ purity) by the usual method. The other reagents used were of the first grade or the special grade when necessary.

\section{Preparation of Fused Salt Solution and Experimental Method}

The water contained in fused salt solutions interferes with the measurements of absorption spectra because of the formation of hydroxide ion which attacks the quartz glass and oxidizes a metal ion. The authors prepared the fused salt solution in the following way by taking notice of dehydration.

Lithium chloride and potassium chloride were separately dried in a vacuum desiccator for about 2 weeks. The suitable amount of each salt (the mole ratio of $\mathrm{LiCl}$ to $\mathrm{KCl}$ is 59 to 41 ) was quickly weighed out from the desiccator, placed in a fusion cell and heated in an electric furnace, while passing dry chlorine gas. The temperature was gradually raised to $500^{\circ} \mathrm{C}$ and maintained at this temperature for 2 hours to remove volatile impurities and water. The furnace temperature was raised to $650^{\circ} \mathrm{C}$ and then maintained at this temperature for 1 or 2 hours until the salt melted perfectly. Dry argon was passed through the eutectic by bubbling it vigorously for about an hour to remove chlorine and the experimental temperature was finally achieved. Next, $\mathrm{K}_{2} \mathrm{PdCl}_{4}$ was dissolved by adding it directly to the eutectic and the resulting solution was made to flow into the absorption cell under an atmosphere of argon. The absorption cell was transferred to the furnace which had been adjusted to a desired temperature in advance and allowed to stand for a while to reach equilibrium in temperature. Optical densities were measured against the eutectic as reference which was prepared in a manner similar to the sample solution except palladium.

After the spectral measurements, the cell was withdrawn from the furnace and the solution was allowed to solidfy in an atmosphere of argon. The solid was weighed and removed from the cell. The amount of $\mathrm{Pd}$ was determined by the extraction-spectrophotometric method devised by Bode ${ }^{(7)}$. Knowing the palladium content and the density of the eutectic ${ }^{(8)}$, the molar absorptivities were calculated.

\section{Results and Discussion}

\section{Absorption spectra of fused LiCl-KCl eutectic}

The absorption spectra of the eutectic obtained against an inert gas as reference at the temperatures from $400^{\circ}$ and $600^{\circ} \mathrm{C}$ are shown in Fig. 2. It had been considered that a band located at about $38.5 \mathrm{kK}\left(1 \mathrm{kK}: 1000 \mathrm{~cm}^{-1}\right)$ at $400^{\circ} \mathrm{C}$ was almost certainly due to heavy metal ions like $\mathrm{Pb}(\mathrm{II})$ contained in the salts as impurity ${ }^{(9)}$. The red shift observed in the ultraviolet absorption edge with an increase in temperature results from the thermal broadenning of the very intense band of alkali chlorides in the far-ultraviolet region. The decrease in optical density observed at the energy below $25 \mathrm{kK}$ with an increase in temperature is due to the interference caused by the thermal radiation from the furnace. At $700^{\circ} \mathrm{C}$, the optical density in the region, 25 to $12 \mathrm{kK}$, amounts to about 0.05 if one takes curve 1 as the base line.

(7) H. Bode : Z. anal. Chem., 144 (1955), 165.

(8) Yôyuen Busseihyô (Physico-Chemical Constants of Fused Salts) (in Japanese), Ed. The Committee of Fused Salt Chemistry, The Electrochemical Society of Japan, Kagaku Dôjin, Kyôto, (1963), p. 282.

(9) D. M. Gruen and R. L. McBeth : J. Phys. Chem., 66(1962), 57. 


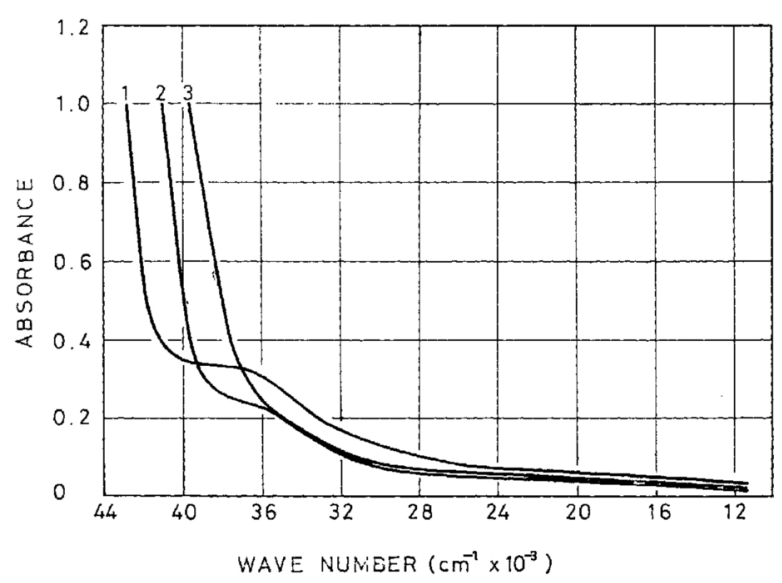

Fig. 2 Absorption spectra of fused LiCl-KCI eutectic at various temperatures. $1: 400^{\circ} \mathrm{C} \quad 2: 500^{\circ} \mathrm{C} \quad 3: 600^{\circ} \mathrm{C}$

This is attributable the effect of the corrosion of the absorption cell.

In view of the above results, it is considered that, with this equipment, the absorption spectra in this eutectic can be measured up to $700^{\circ} \mathrm{C}$ and the accuracy is very good at any temperature below $600^{\circ} \mathrm{C}$.

\section{Absorption spectra of $\operatorname{Pd}(\mathbf{I})$}

The absorption spectra of $\mathrm{K}_{2} \mathrm{PdCl}_{4}$ in the eutectic were measured at various temperatures between $400^{\circ}$ and $700^{\circ} \mathrm{C}$. As shown in Fig. 3, only one absorption band centered at $20.2 \mathrm{kK}$ is observed at $400^{\circ} \mathrm{C}$. It is considered that this band is assigned to a $d$ - $d$ transition as judged from its intensity and position. As shown in Table 1, it is observed that, with an increase in tempera-

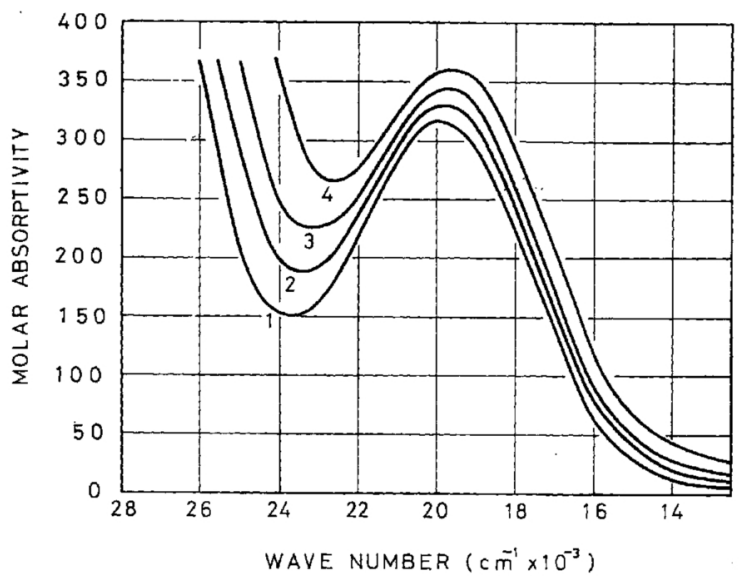

Fig. 3 Absorption spectra of $\mathrm{K}_{2} \mathrm{PdCl}_{4}$ in fused LiCl-KCl eutectic at various temperatures.

$1: 400^{\circ} \mathrm{C} \quad 2: 500^{\circ} \mathrm{G} \quad 3: 600^{\circ} \mathrm{G} \quad 4: 700^{\circ} \mathrm{C}$

Table 1 Molar absorptivity and wave number of maximum absorbance in various media

\begin{tabular}{c|c|c|c}
\hline \hline Solvent & $\begin{array}{c}\text { Temp. } \\
\left({ }^{\circ} \mathrm{C}\right)\end{array}$ & $\begin{array}{c}\text { Max. absorbance } \\
\left(\mathrm{cm}^{-1}\right)\end{array}$ & $\begin{array}{c}\text { Molar } \\
\text { absorptivity }\end{array}$ \\
\hline LiCl-KCl & 400 & 20200 & 315 \\
LiCl-KCl & 500 & 20000 & 330 \\
LiCl-KCl & 600 & 19800 & 345 \\
LiCl-KCl & 700 & 19600 & 360 \\
1M HClO & 25 & 23500 & 220 \\
$2-12 M \mathrm{HCl}_{4}$ & 25 & 21200 & 163 \\
\hline
\end{tabular}

ture, this band shifts toward lower energy side little by little and the molar absorptivity increases gradually. Gruen et al. (2a) have studied in detail the $d-d$ transition bands of $3 \mathrm{~d}$ series transition metal ions in fused $\mathrm{LiCl}-\mathrm{KCl}$ eutectic as a function of temperature and pointed out the following facts. That is to say, with an increase in temperature,

(1) When the co-ordination number of metal ion or the structure of metal complex changes, the shift of absorption maximum amounts to several thouthands in wave number units.

(2) When both of them do not change, the shift amounts to several hundreds.

It seems from the above facts that, with an increase in temperature, the co-ordination number does not change and the structure was little distorted in the case of $\mathrm{Pd}$ (II) complex in the fused $\mathrm{LiCl}-\mathrm{KCl}$ eutectic.

\section{Effect of solvent composition}

The effect of solvent composition on the absorption spectrum was surveyed at $500^{\circ} \mathrm{C}$ over the range from 50 to $75 \mathrm{~mol} \% \mathrm{LiCl}$. In these composition ranges, no change was found in the absorption spectra and thus the structure of $\mathrm{Pd}(\mathrm{II})$ complex was little affected by the composition of the fused salt.

\section{Discussion}

The co-ordination number and the structure of the transition metal complexes in fused salt solutions can be discussed by either of the following two approaches;

(1) the method based on the comparison of the absorption spectra in a fused salt solution with those in an aqueous solution ${ }^{(10)}$,

(2) the method based on "Host Crystal Lattice(2a)".

The method (1) is effective in the case where a metal complex has a simple co-ordination structure which is the same in a fused salt solution as in an aqueous solution. The method (2) is a direct experimental approach for the establishment of the co-ordination structure. That is, some of metal ions in double chloride matrix of known structure like $\mathrm{Cs}_{2} \mathrm{ZnCl}_{4}$ are replaced with the metal ions under discussion and the co-ordination structure is determined by the comparison of the absorption spectra of the isomorphously substituted crystal, of its fused state, and of a fused salt solution. The method (2) is superior to the method (1) but it is limited experimentally because the suitable crystal lattices have to be discovered.

Let us consider the species of $\mathrm{Pd}$ (II) in the eutectic by comparing these absorption spectra with those in aqueous solutions. The absorption spectra of $\mathrm{K}_{2} \mathrm{PdCl}_{4}$ dissolved in the eutectic, $1 \mathrm{~mol} \mathrm{HClO}_{4}$, and $12 \mathrm{~mol} \mathrm{HCl}$ solutions are shown in Fig. 4 and the maximum absorbance and the molar absorptivity are shown in Table 1. By comparison of these absorption spectra, it is assumed that the species in the eutectic is the same as in $2 \sim 12 \mathrm{~mol} \mathrm{HCl}$ solutions because of the following reasons. That is, the difference in wave number of the maximum absorption between room temperature and $400^{\circ} \mathrm{C}$ agrees

(10) G. Harrington and B. R. Sundheim : Ann. N. Y. Acad. Sci., 79 (1960), 950 . 


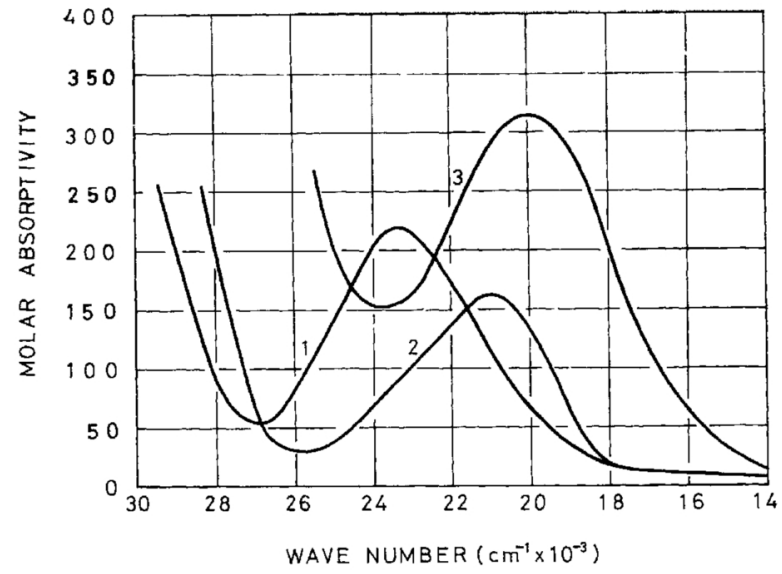

Fig. 4 Absorption spectra of $\mathrm{K}_{2} \mathrm{PdCl}_{4}$ in various media. $1: 1 \mathrm{M} \mathrm{HClO}_{4} \quad 2: 12 \mathrm{M} \mathrm{HCl} \quad 3: \mathrm{LiCl}-\mathrm{KCl}$ eutectic at $400^{\circ} \mathrm{C}$

approximately with the amounts of shift from $20.2 \mathrm{kK}$ at $400^{\circ} \mathrm{C}$ to $19.6 \mathrm{kK}$ at $700^{\circ} \mathrm{C}$ and the position of maximum in a fused salt solution is generally lobserved in the lower energy than that in an aqueous solution or a solvated crystal if these bands are assigned to belong to the same transition ${ }^{(2 a)}$.

For the species of $\mathrm{Pd}$ (II) in aqueous solutions containing various amounts of chloride ion, Sandell et al.(11) assumed that the band centered at $21.2 \mathrm{kK}$ was attributed to the formation of $\mathrm{PdCl}_{5}^{3-}$ and $\mathrm{PdCl}_{6}^{4-}$ and the band at $23.5 \mathrm{kK}$ to $\mathrm{PdCl}_{4}^{2-}$. On the other hand, J $\phi$ rgensen ${ }^{(12)}$ showed that the band at $21.2 \mathrm{kK}$ was due to the formation of $\mathrm{PdCl}_{4}^{2-}$ and the band at $23.9 \mathrm{kK}$ to

(11) A. K. Sundaram and E. B. Sandell : J. Amer. Chem. Soc., 77 (1955), 855.

(12) C. K. J $\phi$ rgensen : Absorption Spectra and Chemical Bonding in Complexes, Addison-Wesely Publishing Company, Inc., Reading Mass, (1962), p. 259, 287.
$\mathrm{Pd}\left(\mathrm{H}_{2} \mathrm{O}\right)_{2} \mathrm{Cl}_{2}$. Thus, the conclusions concerning both of the co-ordination number of $\mathrm{Pd}$ (II) ion and the structure of $\mathrm{Pd}$ (II) complex in HCl solution differ with the authors. Consequently, it is difficult to determine the species in the eutectic by comparison with the absorption spectra in aqueous solutions. The best to say from the experimental results is that the species in the eutestic is the same as in $2 \sim 12 \mathrm{~mol} \mathrm{HCl}$ solutions.

\section{Conclusion}

To measure the absorption spectra of a fused salt solution, a high-temperature cell assembly was constructed and the absorption spectra of $\mathrm{Pd}$ (II) in fused $\mathrm{LiCl}-\mathrm{KCl}$ eutectic were measured with this device attached to a spectrophotometer. From the above results, it has become apparent that the reproducible and accurate measurements can be made up to $600^{\circ} \mathrm{C}$. But, above $600^{\circ} \mathrm{C}$, it is difficult to measure the absorption spectra accurately because the corrosion of the absorption cell is enhanced by the presence of small amounts of water. Consequently, for the purpose of the measurements at a temperature higher than $600^{\circ} \mathrm{C}$, it is necessary to remove even a trace amount of water from fused salt solutions and to use a sealed absorption cell.

It has been assumed from the comparison of the absorption spectra in fused salt solutions and those in aqueous solutions of high chloride concentration that the species of $\mathrm{Pd}$ (II) in the eutectic is the same as in $2 \sim 12 \mathrm{~mol}$ $\mathrm{HCl}$ solutions. However, it is difficult to identify the species in the eutectic only by comparison with the absorption spectra in $\mathrm{HCl}$ solutions. For the purpose of the determination of the co-ordination number and the structure of $\mathrm{Pd}$ (II) complex in fused salt solutions, the method based on "Host Crystal Lattice" will be considered. 